\title{
The Application of Traditional Window Lattice Culture into Modern Interior Design
}

\author{
Hongxing Yi \\ City College of WUST, Wuhan, China \\ lucyyhxc@126.com
}

Keywords: Tradition; Modern; Window lattice culture; Interior design

\begin{abstract}
In the long history of China, the window lattice culture has been inherited for thousands of years. It is an integral part of Chinese excellent traditional culture and has far-reaching influence. From the perspective of traditional window lattice in China, we can understand the different cultural connotations of different patterns. Through the in-depth analysis of the traditional window lattice patterns, we can realize the re understanding of window lattice culture. Refining and innovating the traditional window lattice pattern. Combined with modern building materials and modern design techniques, the window lattice culture can be effectively integrated into modern interior space design to realize the combination of tradition and modernity. It can not only create a more comfortable modern living environment, but also carry forward the Chinese excellent national culture.
\end{abstract}

\section{Introduction}

For thousands of years, window processing has become a unique architectural cultural symbol.

Window lattice culture is an integral part of Chinese excellent traditional culture. It exists in every field and every corner of life.

In a country with a long history, window lattice, which concentrates the essence of history and culture, has placed people's yearning for a better life and inherits the endless historical context.

In the process of interior design, the culture of window lattice is integrated into it, and they are valued, studied, preserved and treasured, so that the excellent national culture can be passed down.

\section{Analysis of Window Lattice Culture}

What is the Window Lattice. The window is more open and bigger from the original hole. In order to make the structure firm, add a separate line to the middle of the hole. These lines are known as "lattice". Lattice, including window, door window, and other parts of the heart. The wooden strips of these cores are carefully carved into patterns, which are often referred to as "window lattice" together with windows. So window lattice, also known as pane, is the frame structure design of Chinese traditional wooden buildings. In addition to lighting, ventilation and other functions, there are important decorative functions.

The Origin and Development of Window Lattice. According to the Western Zhou Dynasty, a simple carving pattern symbolizing people's prayer is beginning to appear on the window lattice. In the Song Dynasty, the partition fan was widely used, its function was perfect, and the combination style of the lattice was rich and varied. From the Yuan Dynasty to the Mongolian, Han, Liao and Jin Dynasties, the culture of window lattice became more diversified and mature. During the period of the Ming and Qing Dynasties, the art of window lattice entered a prosperous period. There were various complex and complicated patterns and ornaments of trees and flowers, landscape, historical figures, and auspicious characters, and the ornaments were crisscross. Because of the blend of culture, many Chinese and western buildings appeared in the Ming and Qing Dynasties, the decorative methods of the window lattice were also more flexible, and the window lattice pattern had a higher aesthetic value in the art.

Types of Traditional Window Lattice Patterns. The traditional window lattice is mainly made of wooden structures. Its structure is very sophisticated. It is made in relief, through carving, saving and 
inserting, and so on. Usually, it is carved with wire grooves and various patterns, constituting a wide variety of beautiful patterns.

The common patterns are: well, moire, hexagonal, subcharacter, flower knot, one yard and three arrows, plate length, three cross six, double cross four, ice crack, plum blossom, grid, cross, diamond, windmill, straight lattice, sleeve ring, rhombus pattern, octagonal, quadrangle, tortoise brocade, begonia, ruyi, set square, lying silkworm, lantern brocade, step by step brocade, round mirror, ten thousand characters, etc.

These patterns are not only very decorative and interesting, but also of high artistic value, as if to attract people in front of the window to stay, carefully observe the charm of it. People stroll through the window lattice, see the beautiful scenery outside, as if to appreciate a picture in the frame, hanging on the wall, both poetic and picturesque.

The Moral of the Pattern of the Traditional Window Lattice. The pattern of traditional window lattice uses pictograph, understanding, homophony, metaphor, analogy, symbol and other techniques to express moral meaning, reflecting the wishes and blessings of people's hearts. Here are several commonly used motifs:

The characteristics of the "back pattern" pattern are a circular or square circular pattern with vertical lines. It is like the word "back". Its connotation has the meaning of safe return, meaning longevity and auspiciousness. This kind of window lattice pattern gives people a kind of inspiration which can give encouragement in the cause, not afraid of setbacks and failures, so long as the courage to do it will be successful connotation. It also implies the continuous progress of the owner's business, happiness and longevity are far-reaching. (Fig. 1)

The pattern of "three cross six" is formed by intersecting the straight lattices and the diagonal lattices, forming numerous equilateral triangles. Each group of triangles has six petals of rhombus, symbolizing the orthodox state power, the connotation of heaven and earth, and the meaning of the four sides. It is a symbol that implies the birth of all things at the intersection of heaven and earth. In addition, there are two lattice intersect called "double cross four". (Fig. 2) (Fig. 3)

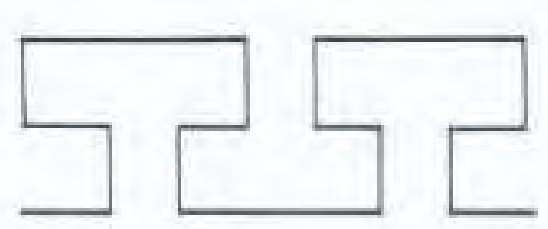

Figure 1. Finite " back pattern " pattern

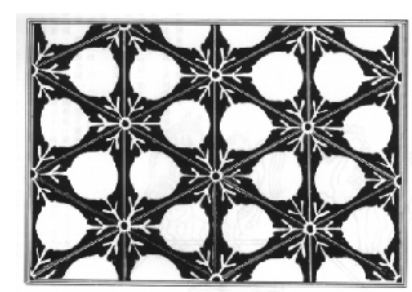

Figure 2. Finite "three cross six" pattern

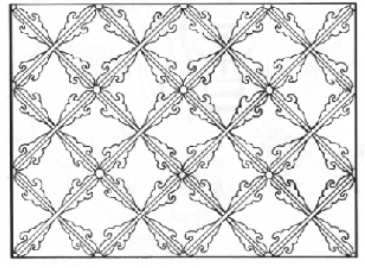

Figure 3.

Finite"double cross four" pattern

The "windmill" pattern is a symbol of the shape of the wind wheel. It is the symbol of flowing air between heaven and earth. The windmill accepts the wind and converts it into power for people to produce, and it becomes a tangible object for people to get wealth. It symbolizes that there is no end to the source of power and wealth given by God. (Fig. 4)

The vertical lines in the "straight lattice" pattern signify the integrity of the owner of the building, and a symbol of the person watching the outside in full view, and anything hidden will be discovered, so that the master will not be deceived by anything and will not suffer loss. And get safe. (Fig. 5)

Begonia is known as the fairy in the flowers by the ancient people, and has the reputation of beauty. The "begonia" pattern is graceful and graceful, and has a unique style. It also symbolizes the fruits of autumn harvest and is also an important part of the four flowers. (Fig. 6)

"Step by step" pattern of brocade lattice is a regular geometric pattern, mainly composed of straight and horizontal lattice. Straight lattice and cross lattice independent vertical and horizontal, each end teasing each other in the middle and side of the formation of T-shaped, straight, the cross lattice from the foreign minister and short together to form a step by step change in the pattern. The moral is to move up the road and have a bright future. (Fig. 7) 


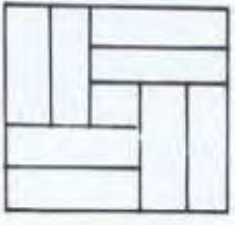

Figure 4. Finite "windmill" pattern

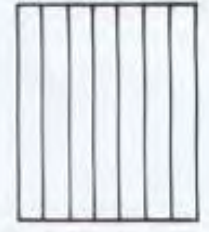

Figure 5. Finite "straight lattice" pattern

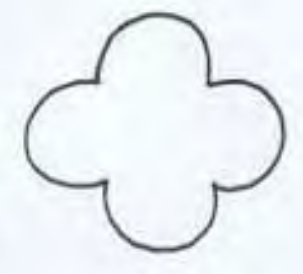

Figure 6. Finite "begonia" pattern

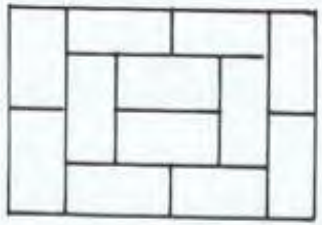

Figure 7. Finite "step by step" pattern

In addition, there is a well-word pattern is the building and well-hostel corresponding, symbolic auspicious. Moire pattern loop turn, extremely varied, is a more pleasing pattern symbol, meaning rising. The pattern of tortoise brocade is the pictogram of turtleundefineds shell in rivers, lakes and seas, and it is the symbol of the divine emissary in the universe. Not only the pattern is regular and beautiful, but also the connotation of health and longevity, no disaster and peace, can be protected by the northern Xuanwu god. A pattern of Asian characters signifies honor. The design of plum blossom represents the character of a gentleman. Flower knots symbolize beauty. Two diamond-shaped compression angles overlap the square victory pattern to express the firm love. The pattern of the lantern indicates a bright future. Ten thousand character pattern is presented a rotating form, swastika four ends of the extension, repeated, meaning everything auspicious, boundless longevity. In some large family houses and the windows of the ancestral hall, there are also vivid birds, flowers, insects, landscapes, characters and stories.

\section{Integration of Traditional Window Lattice Design and Modern Interior Space Design}

Chinese traditional window lattice pattern has unique historical culture and artistic charm. It profoundly reflects the social mainstream ideology that people pray for auspiciousness and avoid disaster. It expresses people's thinking about the philosophical nature of life. Traditional window lattice patterns are widely used in modern interior design.

In the study of the traditional window lattice, we should grasp its characteristics and advantages, analyze it from different emphases, determine different design schemes, and meet the requirements of modern interior design more comprehensively.

In the Chinese style interior space, the traditional window lattice patterns are used more directly. Some of them are used in the space facade partition, some are directly used as wall decoration graphics, which make the whole space simple and elegant, full of traditional cultural charm.

Refining and generalizations is to simplify and summarize traditional window lattice patterns, and then apply them to modern interior space. In modern interior space design, the traditional window lattice patterns are simplified and summarized by refining and summarizing methods, and then applied to various interfaces.

The Application of a Single Window Lattice Pattern. In the design of some modern indoor space, the symbolic features of the traditional "back pattern" pattern can be extracted and generalized to the display frame. These patterns will divide the display frame to form different regions and produce a more stereoscopic effect. This method makes the display rack and the whole space have the characteristics of traditional culture, but the simple abstract lines show a sense of modernity. (Fig. 8)

In the design of the living room space, the sofa background wall is integrated with the combination of three hand and six styles and double cross four patterns. This innovative pattern gives people regular geometric figure brocade and regular pictographic brocade. The geometric pattern is the expression of static feeling, and the pictographic pattern has the connotation of movement. Combined with the symmetrical shape of the entire wall, the whole space is not only simple but also modern. (Fig. 9) 


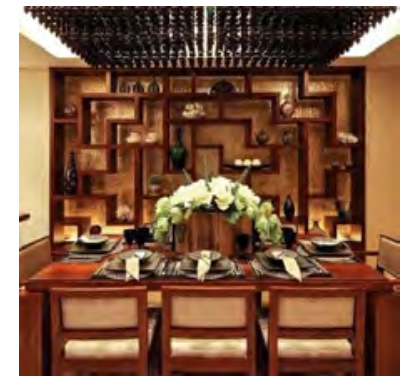

Figure 8. Finite the use of "back pattern" pattern

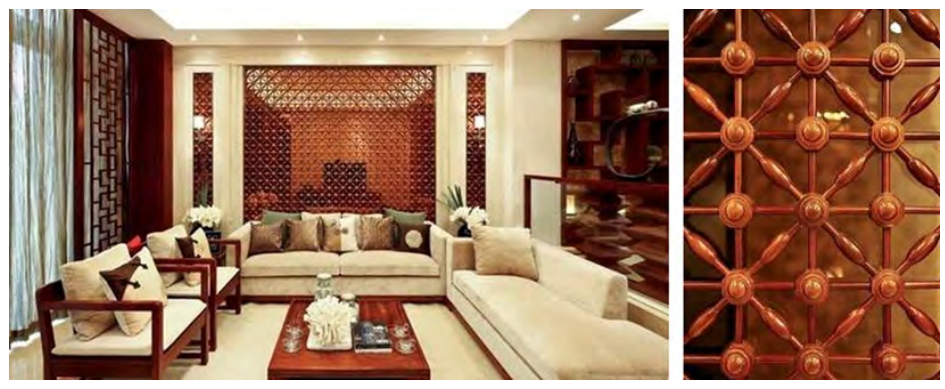

Figure 9. Finite the use of "three cross six" pattern

The pattern of the straight window lattice will give people a sense of simplicity by standing on the window with its unbent and vertical lines. In the design of indoor space, the short horizontal bar is inserted into the straight lattice to get an innovative pattern. The circular leak window is combined with this new pattern to form a beautiful partition. Decorated with a pot of bamboo, the integrity of the owner is shown, and the cultural atmosphere in the room is very rich. In the interior space design, the direct lattice design is mostly applied to the partition, and sometimes it is also applied to the design of the theme wall, such as the design of the TV background wall and the head wall of the bedside. (Fig. 10)
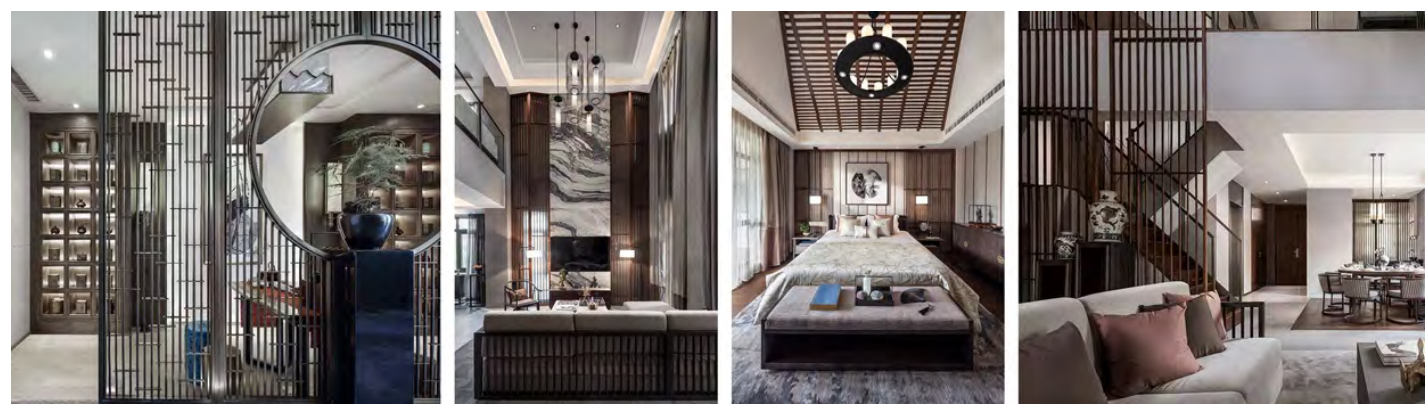

Figure 10. Finite the use of "straight lattice" pattern

"Begonia" pattern door and window lattice heart flower is a symbol of colourful beauty. The flower can be used as the main pattern of the whole flower and can also be used as an auxiliary pattern. Indoor space is the use of a large flower of Begonia to make a window, and then with the small crabapple lattice flowers, designed a block of carved wooden frame, cleverly separated two spaces, increasing the width of the field of vision. It can enrich the whole spatial pattern, and is full of the charm of traditional culture. Its connotation is very beautiful and its meaning is infinite and auspicious. From the perspective of the overall style, modern times are permeates with simplicity, showing the introverted atmosphere and elegance of the family. (Fig. 11)
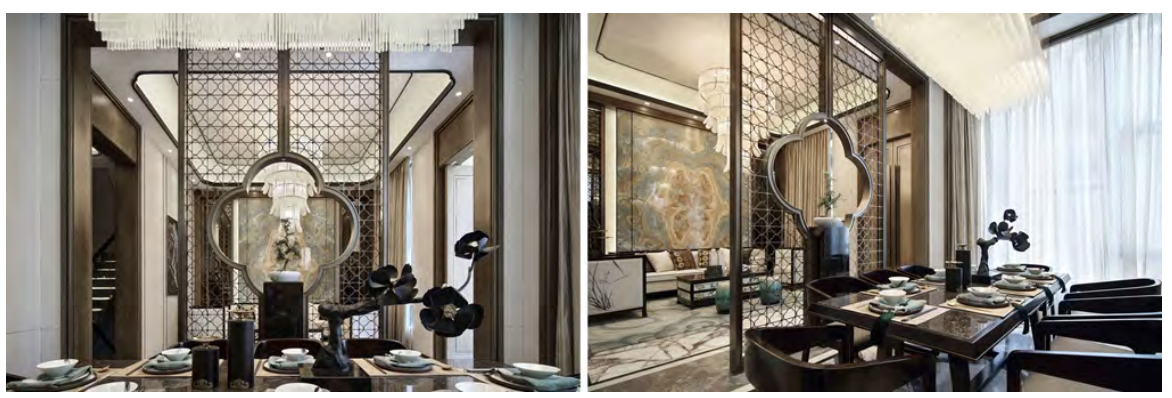

Figure 11. Finite the use of "begonia" pattern

The Comprehensive Application of Various Window Lattice Patterns. In the design of interior space, the traditional symbols of window lattice pattern can be separated by the method of reorganization and reconstruction, and then these symbols can be rearranged and combined by 
dehumidification, refinement, deformation, reconstruction and so on, to make them more adaptable. In this way, the shape of the wall can be more Chinese style characteristics, and in order to enrich the sense of the metope modeling, we can mix and match various window lattice patterns to form a stronger visual effect. (Fig. 12)
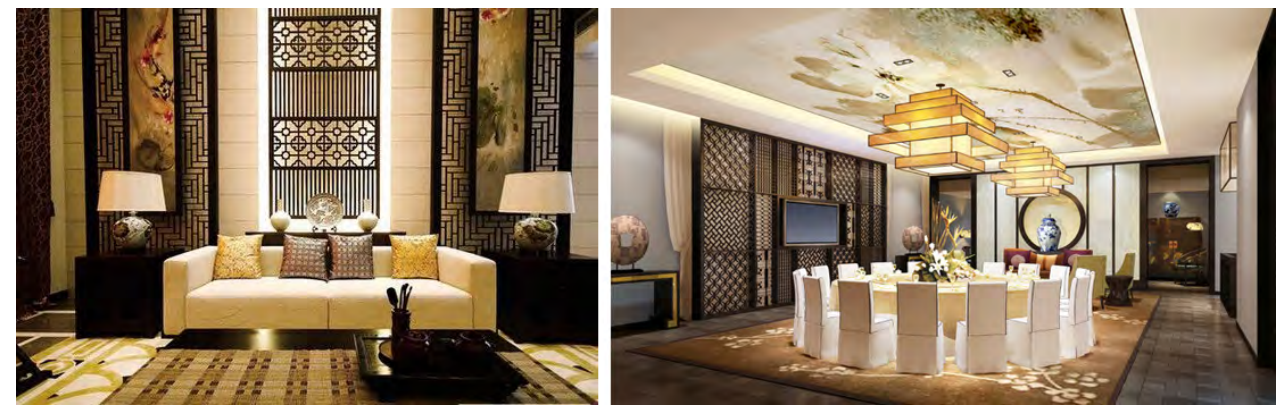

Figure 12. Finite the comprehensive application of various window lattice patterns

\section{The Innovation of the Traditional Window Lattice in the Interior Design}

In today's society, Chinese traditional culture is gradually impacted by foreign culture in the process of continuous development. It inspires people to think new forms of traditional art forms and transforms and uses the aesthetic and concept of modern people to make it new vitality.

The application of Chinese traditional window lattice patterns in modern interior space has been given more rich design language, reflecting the cultural characteristics of the times. In the modern interior design, the Chinese traditional window lattice pattern is used to represent the traditional Chinese style.

Abstract and generalize is the common means of modern interior space design. This kind of extraction is generally divided into two types. One is the extraction of "meaning". It is necessary to study and examine the profound meaning and connotation expressed by the traditional window lattice pattern, and then to extract "meaning" according to the characteristics of the interior space. The other is the extraction of "shape", which simplifies, merges, generalizes and applies the traditional window lattice pattern to the design. This method can make the interior space have some characteristics of the traditional window lattice pattern, but it is not directly copied. Moreover, we can omit the complicated details, grasp the charm and essence of the original pattern, and abstract and generalize it to make it more suitable for the modern space environment.

For example, when a certain window lattice pattern is applied to the screen, the middle part of the screen can be removed and replaced by a glass with a strong modern sense, which not only expresses the characteristics of Chinese traditional culture, but also enhances the modern sense of space. Another example is that some traditional window lattice patterns do not conform to modern aesthetic standards, so we can change its structure when we design the interior, or make use of a certain morphological feature of it. It produces a new design form by means of partial or global deformation. Therefore, we not only understand and grasp the historical tradition; we also have a new tradition. There must be a lot of uncontrollable stereotypes, but we have to modify and eliminate them, create new understanding on that basis, and then form part of the tradition. Therefore, tradition determines us, and we also determine tradition.

\section{Summary}

Chinese traditional window lattice pattern, as a traditional art form, records the aesthetic features and ideas of each dynasty, with distinctive features of the times and regional characteristics, and also deeply embodies the development and evolution of Chinese culture and art. Therefore, its value lies not only in its rich content, various forms and strong decoration, but also in its aesthetic consciousness and national cultural spirit. Today, the extensive use of Chinese traditional window lattice patterns in indoor space 
embodies people's profound feelings for national culture, and will also make interior design decoration art more mature. At the same time, in the process of the application of the traditional window lattice pattern in the interior space, we should also consider certain ways, use the pattern form selectively, pays attention to the agreement between the pattern and the space environment. To a certain extent, we should refine traditional window lattice patterns, and pay attention to the adaptability of traditional patterns to modern space. To a certain extent, the traditional window lattice pattern should be refined, the pattern design should be innovated, and the adaptability between the traditional pattern and the modern space should be improved. In the process of displaying the beauty of the traditional window lattice pattern, we should pay attention to the communication of its cultural connotation, realize the collision of modern culture and history and culture, meet the actual needs of life, create a healthy and comfortable living environment, and meet the needs of people's physiological and psychological aspects.

\section{References}

[1] Q.J. Wang: Chinese Window Lattices and Forms (Chongqing Press, China 2007), p.16-214.

[2] C.N. Peng: Traditional Chinese Architecture -- Doors and Windows (Heilongjiang Fine Arts Publishing House, China 2005).

[3] Y.Z. Lu: The Art and Fabrication Technology of Wooden Doors and Window Lattices in Ancient Buildings (China Architecture \& Building Press, China 2008), p.21-62.

[4] J.L. Pan: Chinese traditional window lattice (People's Fine Arts Publishing House, China 2004). p.11-129.

[5] J. Lu: The Art of Ancient Chinese Architecture: 1 door and window Art Volume (SichuanRenmin Press, China 2011), p.68-155.

[6] W.M. Qi and H. Mi: Doors \& Windows, (2016) No.6, p.35-38.

[7] B.J. Ma: The Construction Technology of Chinese Ancient Architecture Wood (Science Press, China 2017).

[8] M. Peng: Modern Decoration(Theory), (2014) No.6, p.125-126.

[9] Q.F.. Zhu: Modern Decoration(Theory), (2017) No.1, p.45-46.

[10]Y.P. Jin: New West, (2014) No.22, p.89.

[11] M.M. Jiang: Chinese traditional visual elements-- application and Research of window lattices in Modern Interior Design (MS., Yanshan University, China 2014), p.15-53.

[12]X.L. Wang: Application Research of Chinese traditional window pattern in Modern Interior Design (MS., Jingdezhen Ceramic Institute, China 2013), p.5-24.

[13] Information on http://www.cool-de.com/ 